\title{
E-band slotted microstip patch antenna array for 5G broadband applications
}

\begin{abstract}
An antenna is one of solution for wireless devices which can be proposed for future $5 \mathrm{G}$ systems for high data rate broadband, communications. The antenna system can be design for multiple-input-multiple-output (MIMO) system at a waveband of millimeter ( $\mathrm{mm}$ ) range. The MIMO system consists of the mm-wave array of 2 by 1 slot antennas. The combination of the antenna array system covers the range of frequency from $83.581 \mathrm{GHz}$ to $86.483 \mathrm{GHz}$ of mmwave band at $85 \mathrm{GHz}$. The antenna array dimension is $0.94 \mathrm{~mm}$ by $2.28 \mathrm{~mm}$ by $0.16 \mathrm{~mm}$. Results obtained from simulation across the $5 \mathrm{G}$ band showed peak gain values of $5.82 \mathrm{dBi}$, VSWR of 1.09 with $-10 \mathrm{~dB}$ return loss of $-27.5 \mathrm{~dB}$.
\end{abstract}

Keyword: MIMO; mm-wave; Wide-band antenna; Antenna array; Slot 